\title{
The Effects of Academic Advising on Juniors and Seniors of English Department at Balkh University
}

\author{
Sayed Mustafa Zewary \\ Assistant Professor, English Language and Literature Department, \\ Balkh University, Mazar-e-Sharif, Balkh, Afghanistan
}

\begin{abstract}
Academic advising is the process between the students and academic advisors who exploring the value of a general education, reviewing the services and policies of the institution, discussing educational and career plans to make appropriate course selection goals for their students. Some studies have been conducted on academic advising and its effects on students' academic development. Therefore, the present paper is an attempt to contribute the previous studies by presenting the factors that academic advising has an impact on students' academic development. Thus, this paper will explore whether academic advising is efficient to the students or not. For this purpose, previous studies were reviewed, and the questionnaire was shaped. The participants were selected randomly who are the juniors and seniors $(61 \%$ females and 39\% males) of English Department at Balkh University. In the long run, the analysed data revealed that the functions of academic advising have impact on students', success, development, educational outcomes, students' satisfactions and students' retention.
\end{abstract}

Keywords: academic success, academic development, educational outcome, student's satisfactions and speculative retention

\section{Introduction}

Academic advising is the process between the students and an academic advisor who exploring the aim of a general review about student's education, discussing student's educational and career plans to make appropriate course selection goals for them. According to Parget (2011), "A faculty advisor plays an important role to student's academic success by mentoring students throughout their career and by providing them with expert advice and resources to enhance student learning and development." (p. 2)

In addition, good advising has a different meaning for students and students must give advices by someone they can trust and the person who gives advices should be honest and sincere. As Simpson (2013) argued services of academic advising can offer academic advising, career and special services and support to students. Academic advising is designed to assist students achieving academic and personal success through inform decision making and academic planning. Students are assisted to take full advantage of their experience at the university to maximize their potential and realize their personal as well as institutional goals. 
To put it clear, many advisors can become overwhelmed and frustrated while working with students and student's groups, but learning to seek advice from others can be extremely beneficial. According to Dibia and Obi (2013), the positive role of academic advisors is to perform specific functions designed to assist students maximize their potential in the university. Therefore, advisors can help students to understand their roles at various points in life such as the role of student or a citizen in the larger community by helping students develop autonomy, integrity and responsibilities.

\section{Research Questions}

- Is there a relationship between academic advising and students' development?

- Is it important for students to have academic relationship with their academic advisor?

\section{Research Objectives}

1. To discover the roles of academic advising on students' academic development, achievement and success in English department of Balkh University.

2. To explore the important factors about academic advising that effect on seniors and juniors students.

\section{Literature Review}

The more a students' advisor discussed personal and career options, college policies, academic deadlines, study skills and tips, the more likely the student positively developed and had a higher level of satisfaction with college and grade point average (Dlugosh, n.d, as cited in Pargets, 2011). Moreover, academic advising decreases time for students to graduate by improving access to degree requirement. "Academic advising directly affect student's probability of graduating, their major change has indirect effect on grades, and satisfaction with the student role" (Pascarella \& Terenzini, 2005, as cited in Jaradat \& Mustafa, 2017, p. 2).

However, the relationship between students and their advisors is more important. Parget (2011) asserted, "A faculty advisor plays an important role to student's academic success by mentoring students throughout their career and by providing them with expert advice and resources to enhance student learning and development" (p. 2). As Parget (2011) asserted that the result of student's relationship with a faculty advisor is the student's academic success and satisfaction with college and with other students.

In contrast, Cuseo (n.d) asserted the need for student support in the academic planning and decision-making process is highlighted by research findings, which indicate that the three of four students are uncertain about their career choice at college entry. Only 8\% of new students feel they know how to deal with their intended major and over half of all students who enter college with a declared major change their mind before they graduate. Only one senior out of three will major in the same they preferred as a freshman.

According to Barnes and Parish (2017), defining an effective advisory program with an established framework for instruction led to improved awareness and participation by students and faculty. The academic advisory process combined with increased frequency of interaction with focus on the personal and professional growth in addition to academic performance led to improved student satisfaction. 


\section{Methodology}

This study was conducted in two different level of senior's and junior's classes of English Department at Balkh University. The respondents were male and female (i.e. $61 \%$ female and $39 \%$ male). They mention their opinion clearly about the importance of having an academic advising in learning process. The questionnaires were distributed to the students of English Department, and then the data were collected for findings of this research. The data were collected in two ways quantities and qualitatively design, that investigates the effects of academic advising in the academic development of students.

\section{Findings}

After analyzing the questionnaires, the results showed that majority (81\%) are consenting that having academic relationship with an academic advisor has a great impact on students' academic development. On the other hand, $7 \%$ of the participants reported that (No) it is not useful for students that have academic relationship with their academic advisor and $12 \%$ of students were sure that it has an impact or not as shown in Figure 1.

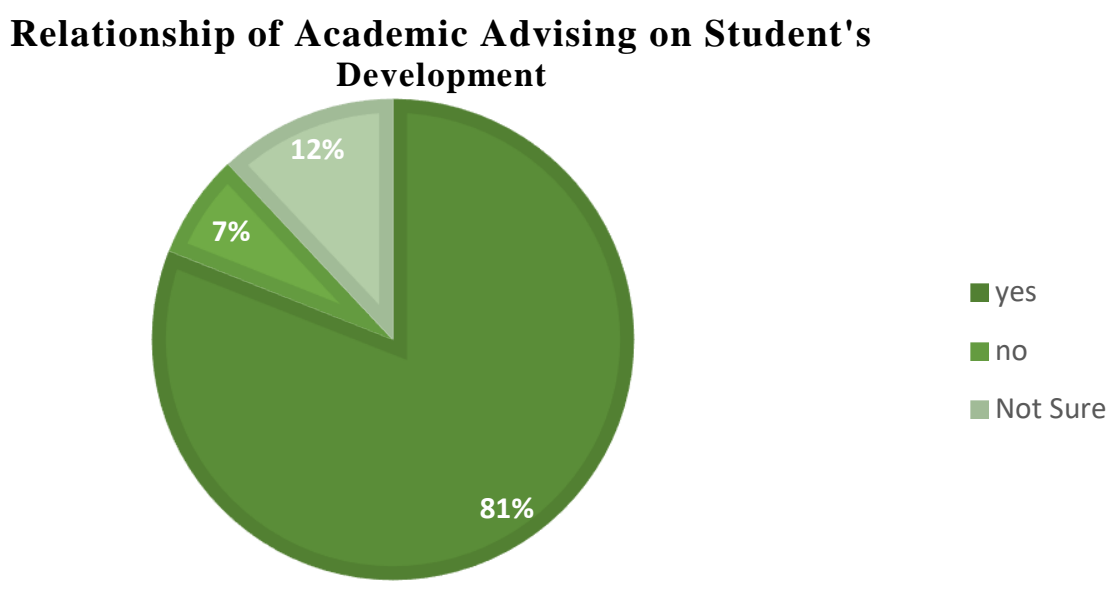

Figure 1. Relationship of academic advising on student's development

According the analyzation, the majorty of students (80\%) responded that academic advising have benefit on students' academic achivement. However, (9\%) of them responded that no it has no beneficent impact on students academic achivement and the rest (11\%) respoded they are not sure as shown in figure 2 . 


\section{Benefit of Academic Advising on Students' Achievement}

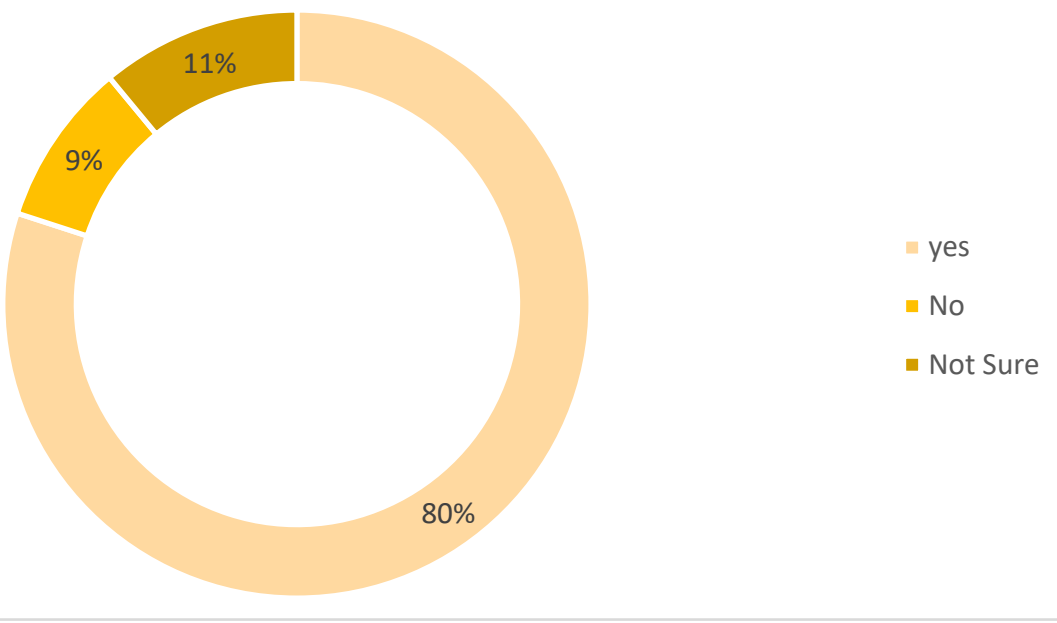

\section{Figure 2. Benefit of academic advising on students' achievement}

Figure 3 shows that it is very important for both senior's and junior's student that should have an academic relationship with their academic advisors and the majority of participants consenting this which is (83\%). In contrast, (12\%) of them were even not sure about this and a few of participates responded negatively in this statement which was (5\%).

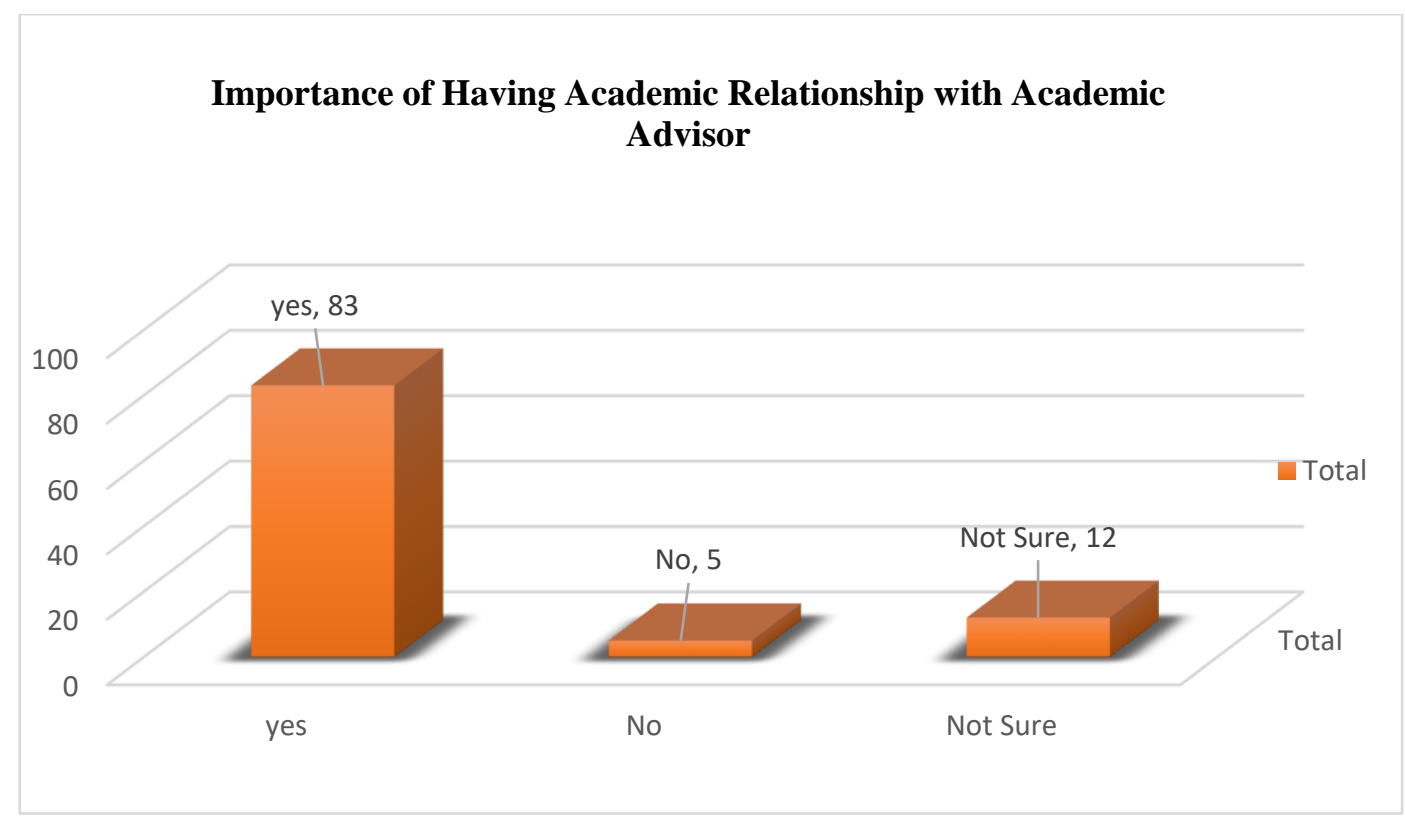

Figure 3. Importance of having academic relationship with academic advisor

Likewise, (71\%) of students shows their agreements that their advisors should listen closely to their concerns and questions. In contrast, $(23 \%)$ of responded was neutral and they were 
not sure whether they should listen or not, but only (6\%) of students was disagree to this point as in figure 4.

\section{Listening of Advisor for Student's Concerns}

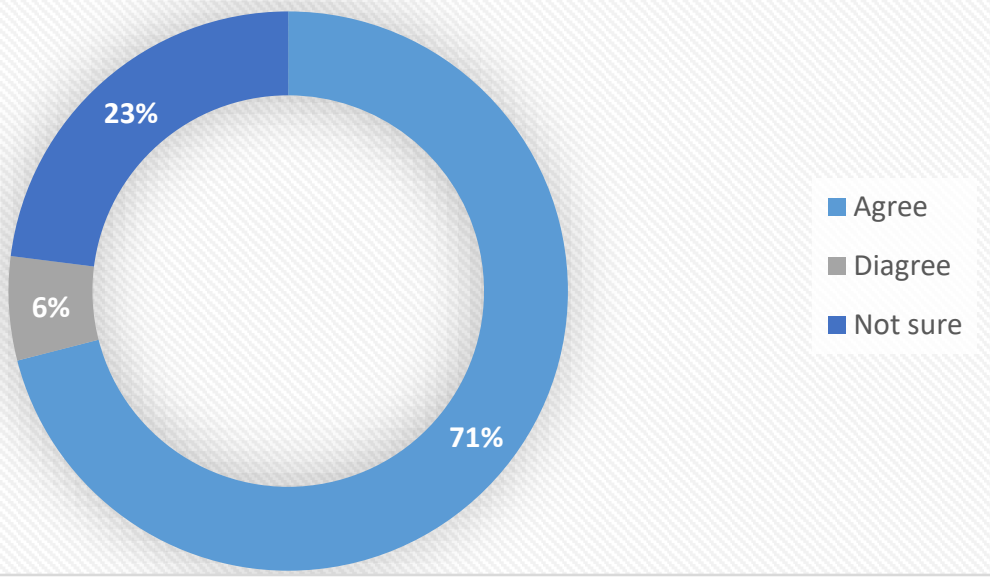

\section{Figure 4. Listening of advisor for student's concerns}

Similarly, the huge amount of students (89\%) responded that their academic advisors should provide useful information about courses. On the other hand, (5\%) shows their disagreement and the rest $(6 \%)$ still were not sure in this point as in figure 5.

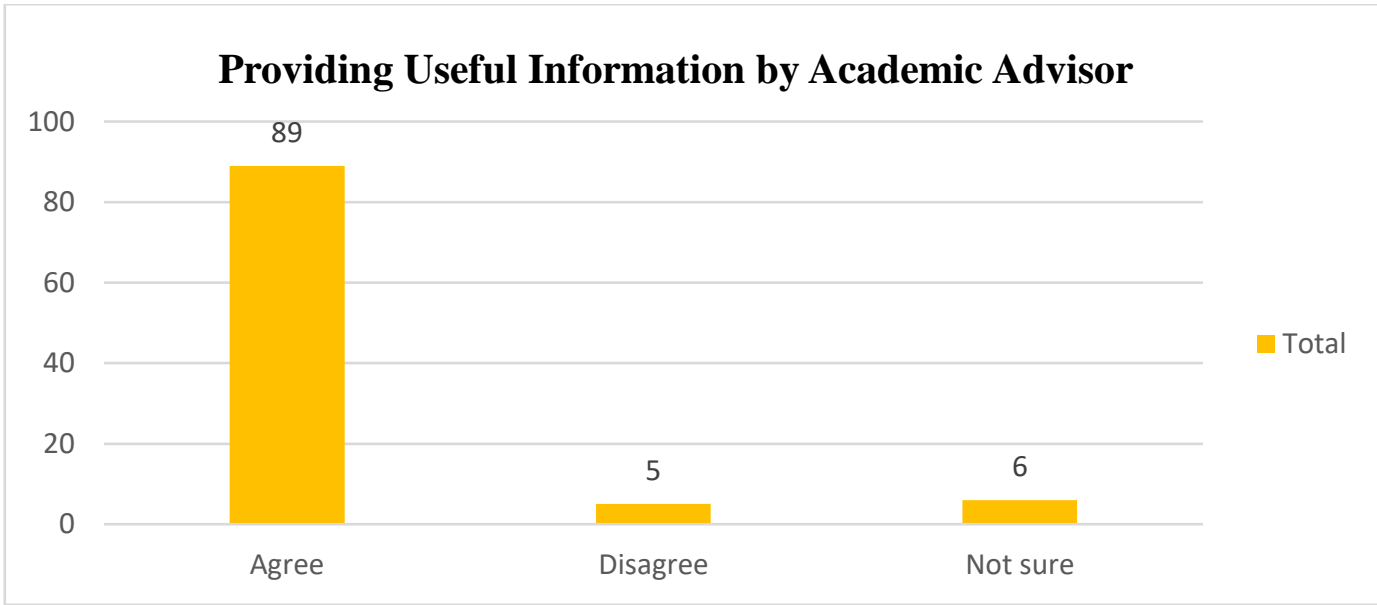

Figure 5. Providing useful information by academic advisor

As a matter of fact, having an academic advisor always has a positive reward for students. Academic advisors help and encourage students in university and academic plans, so it's very important that they should make encourage their students to develop some short-and longterm goals for their post-graduation as well. Therefore, the given figure 6 shows that (60\%) of 
the students agreed to this point. Alternatively, (34\%) of students was not sure, while (6\%) of them was disagreed.

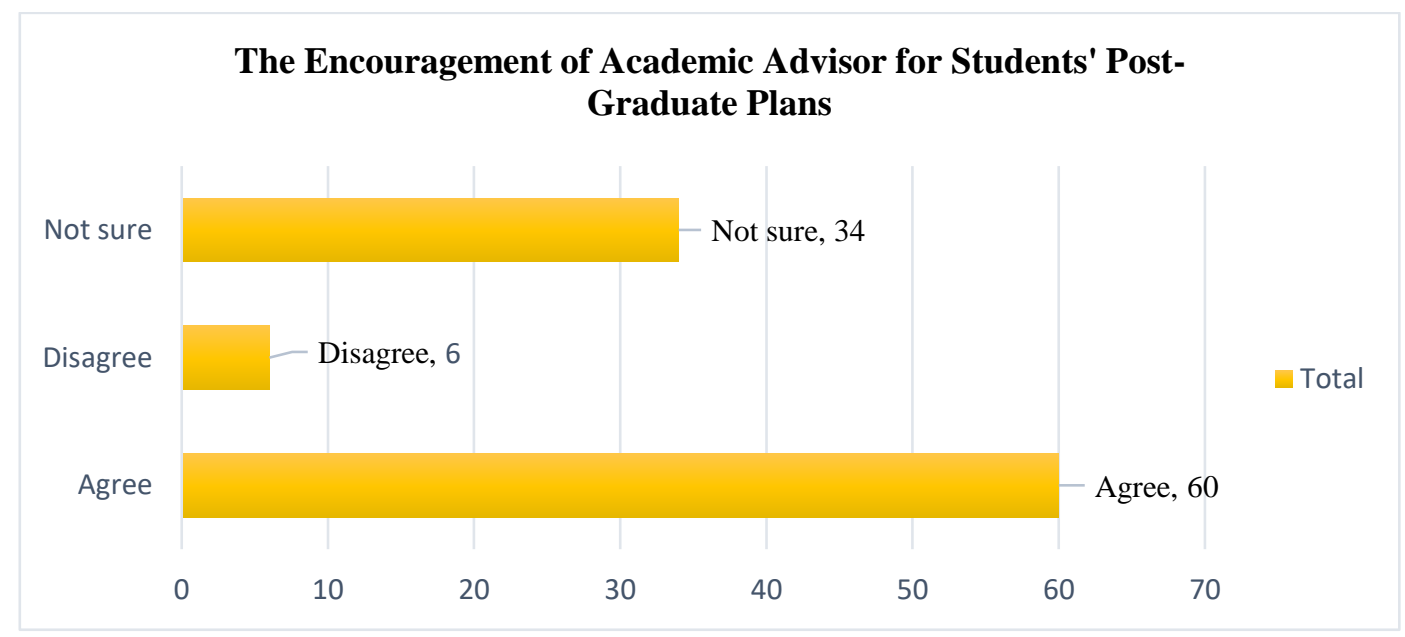

Figure 6. The encouragement of academic advisor for students' post-graduate plans

In addition, all achievement and success of a students will come from performance of that students and it will happen when the advisor help that student about how to perfume academically. Therefore, $(87 \%)$ of students was agreed that their advisor should help them on their academic performance. On the other hand, (10\%) of them was not sure and the minatory (3\%) was disagreed.

\section{Help of Academic Advisor on Students' Academic Performance}

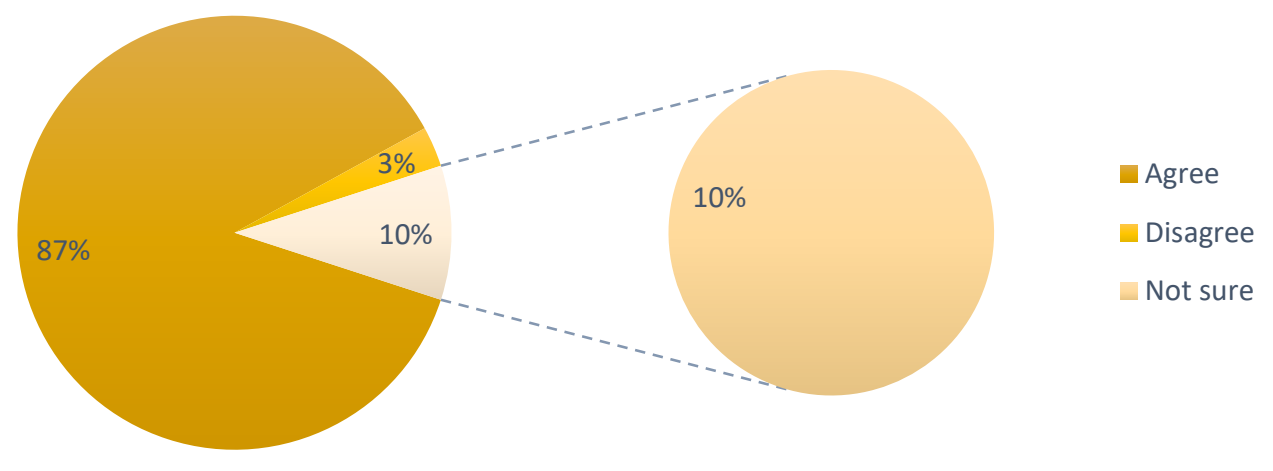

\section{Figure 1. Help of academic advisor on students' academic performance}

\section{Discussion}

From the analysis above, it comes clear that academic advising has a crucial impact for the academic developments of seniors and juniors of English Department in Balkh University. There was ample past research on the effects of academic advising and student development 
and the results of this study are comparable to the results of past research. The researcher was confident that information gathered from the participants of this study does portray an accurate picture of understanding the impact that academic advising has on student development in higher education at university level.

In addition to having a professional relationship between the academic advisor and student, the discussing topics such as study skills, educational success and university policies were increased. Discussing such topics can lead to students' success and students' retention.

Another finding from this study indicates that the more the advisor and student discuss possible career options and courses for the student to take, the more the student positively develops. However, this collaboration not only helps create the relationship between the advisor and the student, but it also allows the student to make his or her own choices in their education. Thus, if the students are more satisfied with the information they have been provided by their advisor, the students' will get more academic development.

As well as, the other finding was that a faculty advisor plays an important role to enhance student's success by mentoring their academic career and providing them with their expert advices. According to Parget (2011), "A faculty advisor plays an important role to student's academic success by mentoring students throughout their career and by providing them with expert advice and resources to enhance student learning and development." (p. 2)

As a conclussion, the factors that have been founded, are very influential factors and have great impact on students' academic development. The study illustrates that how much having an academic advisor will help them for their academic achievement, development, outcome, satisfactions, retention and their academic success. Likewise, the researcher purposefully chooses to include seniors and juniors in this study because they would have a faculty advisor by their junior year and definitely by their senior year. Since the majority of the participants had not been advised by a faculty advisor at all, past research and the results from this study can provide beneficial information about the positive impact that having a faculty advisor can develop students' academically.

\section{Conclusion}

In addition, the data from the literature and questionnaire contributed to find that having an academic advisor has a great impact for the academic development of seniors and juniors of Balkh University and it hold a crucial role in students' academic development. As well as, faculty advising has a significant impact on student development in higher education. Overall, this research study was examined the factors, such as students' academic success, students' development, the effects of academic advising on students' outcomes, students' satisfactions, the importance of appreciate advising and students' retention.

As a final outcome of this research, academic advising can help to increase students' retentions and enrollments due to the attention students receive and the support provided throughout their university career. Moreover, academic advisor can help students to increase their academic success, retention, outcomes and development. Therefore, for a student the best advisor is their instructor. Thus, a faculty advisor plays an important role to enhance student's success by mentoring their academic career and providing them with their expert advices. 


\section{References}

[1] Barnes, L. J., \& Parish. R. (2107). Improving students-perceived benefit of academic advising within education of occupational and physical therapy in the United States: A quality improvement initiative USA. Journal of Educational Evaluation for Health Professions. Retrieved on April 14, 2018 from https://doi.org/10.3352/jeehp.

[2] Cuseo, J. (n.d). Academic advisement and students' retention: Empirical connections \& systemic interventions Marymount college. Retrieved on May 2, 2018 from: http://www.nacada.ksu

[3] Dibia, N. G., \& Obi O. P. (2013). Academic advising and counseling in universities in south east Nigeria: A new perspective. Academic journal of inter-disciplinary studies MCSER publishing, Rome, Italy. Retrieved on April 10, 2018 from: www.mcser.org

[4] Jaradat, M. S., \& Mustafa, M. B. (2017). Academic advising and maintaining major: Is there a relation? Dubai, UAE. College of education, humanities and social sciences. Retrieved on August 4, 2018 from: www.mdpi.com/journal/socsci

[5] Pargett, K. K. (2011). The effects of academic advising on college students' development in higher education. Lincoln, Nebraska. University of Nebraska-Lincoln. Retrieved on March 5, 2018 from: http://digitalcommons.unl.edu/cehsedaddiss/81

[6] Simpson, S. (2013). Advise me! Understanding undergraduate student perceptions of learning in Academic advising Kentucky. University of Kentucky. Retrieved on August 5, 2018 from: https://uknowledge.uky.edu/comm_etds/10 